\title{
Feasibility of primary percutaneous coronary intervention via the distal radial approach in patients with ST-elevation myocardial infarction
}

Yongcheol Kim ${ }^{1, *}, \dagger$, Jun-Won Lee ${ }^{2,}$, Sang Yeub Lee ${ }^{3}$, Jang-Whan Bae ${ }^{3}$, Sang Jun Lee ${ }^{2}$, Myung Ho Jeong ${ }^{1}$, Seung-Hwan $\mathrm{Lee}^{2}$, and Youngkeun Ahn ${ }^{1}$

${ }^{1}$ Division of Cardiology, Department of Internal Medicine, Chonnam National University Hospital, Gwangju; ${ }^{2}$ Department of Internal Medicine, Yonsei University Wonju College of Medicine, Wonju; ${ }^{3}$ Department of Internal Medicine, Chungbuk National University College of Medicine, Cheongju, Korea

Received: December 8, 2019 Revised : January 13, 2020 Accepted: January 23, 2020

\section{Correspondence to} Youngkeun Ahn, M.D. Division of Cardiology, Department of Internal Medicine, Chonnam National University Medical School, 160 Baekseo-ro, Dong-gu, Gwangju 61469, Korea

Tel: +82-62-220-4764

Fax: $+82-62-224-4764$

E-mail: cecilyk@hanmail.net https://orcid.org/0000-00032022-9366

\section{*These authors contributed equally to this work.}

${ }^{\dagger}$ Current affiliation: Division of Cardiology, Department of Internal Medicine, Yonsei University College of Medicine and Cardiovascular Center, Yongin Severance Hospital, Yongin, Korea

Background/Aims: Recently, distal radial approach (DRA), called as snuffbox approach, has gained the interest of interventional cardiologists, but there is a lack of data about the feasibility of DRA as an alternative route for primary percutaneous coronary intervention (PCI).

Methods: A total of 138 patients presenting with ST-elevation myocardial infarction (STEMI) in whom primary PCI via the DRA was attempted at three hospitals from October 2017 to September 2019 were analyzed.

Results: The success rate of snuffbox puncture in the setting of STEMI was 92.8\% (128/138). Successful primary PCI via the DRA was achieved in all 128 patients. The snuffbox puncture time, defined as the time interval from local anesthesia induction to successful sheath cannulation, was $2.7 \pm 1.6$ minutes, and snuffbox puncture was performed within 5 minutes in $95.3 \%$ of patients. Moreover, the percentage of the puncture time in the door-to-balloon time was $3.3 \%$. The left DRA was selected in 103 patients (80.5\%), and primary PCI via the DRA was performed using a 6-Fr guiding catheter in 125 patients (97.7\%). There was no major bleeding; however, there were four cases (3.1\%) of access-site complications, including three cases of local hematoma ( $\leq 5 \mathrm{~cm}$ diameter) and one case of local numbness, which improved 3 months later.

Conclusions: In the setting of STEMI, the DRA could be a feasible alternative access route for primary PCI.

Keywords: Radial artery; ST elevation myocardial infarction; Percutaneous coronary intervention; Hemorrhage

\section{INTRODUCTION}

The radial approach for coronary angiography (CAG) and percutaneous coronary intervention (PCI) is preferred owing to several advantages, including reduced vascular complications, patient comfort, and early ambulation, when compared with the femoral approach [1-3]. Moreover, a recent largescale randomized trial demonstrated that the radial approach in patients with acute coronary syndrome was associated with a significantly lower incidence of cardiovascular mortality and major bleeding at 1 year compared 
with the femoral approach [4]. With these advantages, the radial approach is recommended as the standard approach for PCI procedures in most clinical settings [5]. The radial approach is also recommended over the femoral approach when an experienced radial operator performs primary PCI in patients with ST-elevation myocardial infarction (STEMI) [6].

Recently, the distal radial approach (DRA), called as the snuffbox approach, has gained the interest of interventional cardiologists. Data supporting the feasibility of the DRA for CAG and PCI have been published, demonstrating potential benefits over the conventional radial approach in terms of patient and operator comfort, shorter hemostasis duration, less bleeding, and access-site complications [7-9]. The DRA could be considered an alternative access route in selected patients, such as those with a high bleeding risk or renal impairment in whom the radial artery needs to be preserved for arteriovenous fistula creation. However, there is a lack of data about the DRA as an alternative route for primary PCI in patients with STEMI, who often need treatment with potent antithrombotic agents such as ticagrelor or prasugrel or the use of glycoprotein IIb/IIIa inhibitors. As a result, the feasibility of the DRA for primary PCI is still unclear. Therefore, this study aimed to investigate the feasibility of a DRA in patients with STEMI.

\section{METHODS}

\section{Study population}

A total of three experienced radial operators, defined as operators who perform at least $50 \%$ of all PCI procedures in patients with acute coronary syndrome via the radial approach, participated in this study [2]. The operators attempted the DRA in patients with STEMI who had a well-palpable pulse in the anatomical snuffbox area. We retrospectively collected data from patients with STEMI who were planned to undergo primary PCI via the DRA at three hospitals between October 2017 and September 2019. STEMI was defined as ST-segment elevation in at least two contiguous leads, with ischemic symptoms and elevated cardiac markers (creatine kinase-MB or tropo$\operatorname{nin} \mathrm{I} / \mathrm{T}$ ). Primary PCI was defined as PCI in patients presenting within 12 hours of symptom onset or $>12$ hours from symptom onset with clinical and/or electrocardiographic evidence of ongoing ischemia [6].

The study protocol was approved by the Institutional Review Board of each hospital (approval number: CNUH2019-185, CR319045, CBNUH-2019-06-010), which waived the requirement for informed consent owing to the retrospective observational study design.

\section{Preparation for the DRA}

Local anesthesia on the anatomical snuffbox was achieved through lidocaine hydrochloride injection by using a 26-gauge needle. Thereafter, puncture was performed by using a 20-gauge 2-piece needle with the through-andthrough or anterior wall puncture technique, or a 21-gauge open needle with the anterior wall puncture technique. After a successful puncture, a 0.025 -inch straight wire or a 0.018 -inch hair wire was inserted, followed by insertion of the 5- or 6-Fr radial sheath (Prelude Radial, Merit Medical, South Jordan, UT, USA; or Radiofocus Introducer II, Terumo Corp., Tokyo, Japan) (Fig. 1A). The selection of the puncture device was left at the physician's discre-
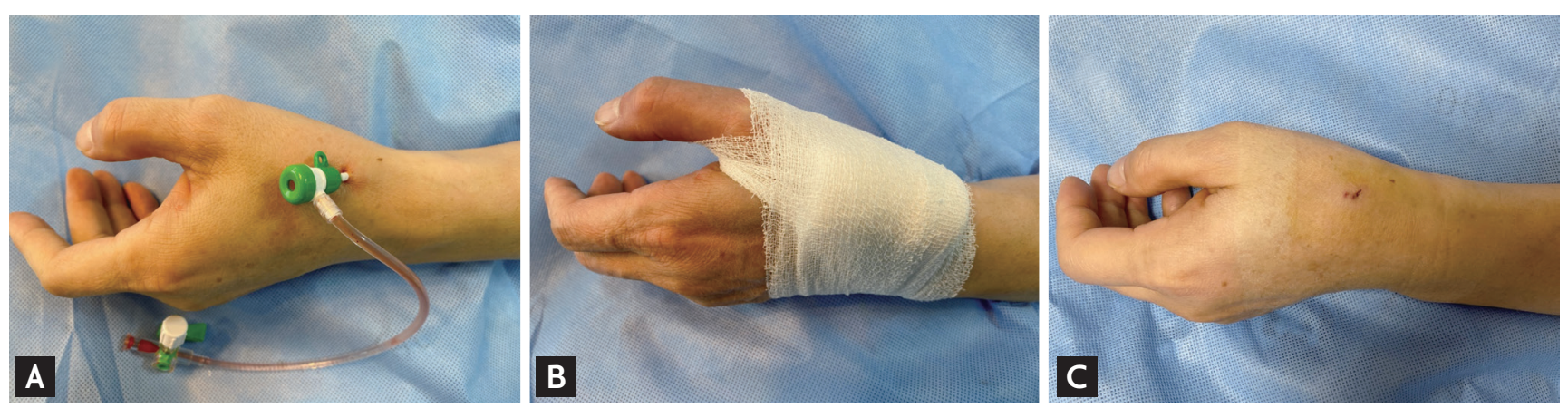

Figure 1. Inserted 6-French sheath via the left distal radial approach (A), hemostasis by compressive bandage method (B), and no access-site hematoma after 3 -hour hemostasis (C). 
tion. Hemostasis was obtained using a $4 \times 4$-inch sterile gauze dressing wrapped with cohesive elastic bandage for 3 hours, according to the method of each hospital (Fig. 1B). Access-site hematoma classified according to the Early Discharge After Transradial Stenting of Coronary Artery (EASY) trial classification and local hematoma defined as EASY classification I ( $\leq 5 \mathrm{~cm}$ diameter of hematoma) (Fig. 1C) [10].

\section{Medical treatment and primary $\mathrm{PCl}$ procedure}

Primary PCI was performed according to the current updated STEMI treatment guidelines. Patients who underwent primary PCI received a loading dose of aspirin (300 mg) and a $\mathrm{P}_{2} \mathrm{Y}_{12}$ receptor inhibitor (180 mg ticagrelor or $60 \mathrm{mg}$ prasugrel or 300 to $600 \mathrm{mg}$ clopidogrel) before the procedure if they were not previously taking these medications. The choice of medication including antiplatelet agents, the use of intravascular imaging guidance or glycoprotein IIb/IIIa inhibitors, and the need for stent implantation were determined according to the clinical decision of physicians. Unfractionated heparin ( 50 to $70 \mathrm{U} / \mathrm{kg}$ ) was administered during the procedure to maintain the activated clotting time at 250 to 300 seconds.

\section{Statistical analysis}

All categorical variables were reported as numbers with percentages. All continuous variables were expressed as means with standard deviations or median with interquartile ranges, when appropriate. Statistical analysis was performed using SPSS version 22.0 for Windows (IBM Co., Armonk, NY, USA).

\section{RESULTS}

The DRA was attempted in 138 patients with STEMI during the study period. The success rate of snuffbox puncture was $92.8 \%$ (128/138). However, the success rate of primary PCI was $100 \%$ in all 128 patients in whom successful snuffbox puncture was achieved (Table 1 ).

Table 2 summarizes the baseline characteristics of 128 patients who underwent successful primary PCI via the DRA. The average age of the patients was $62.3 \pm 10.8$ years, and $85.2 \%$ were men. The median symptom-to-balloon and door-to-balloon (D2B) times were 172 and $70 \mathrm{~min}$,
Table 1. Success rate of snuffbox puncture, diagnostic CAG and primary PCI

\begin{tabular}{|c|c|}
\hline Variable & Value \\
\hline Patients who tried the distal radial approach & 138 \\
\hline Success rate of snuffbox puncture & $128(92.8)$ \\
\hline Patients with failed snuffbox puncture & 10 \\
\hline $\begin{array}{l}\text { Crossover to the conventional radial } \\
\text { approach }\end{array}$ & $7(70)$ \\
\hline Ipsilateral & $5(71)$ \\
\hline Contralateral & $2(29)$ \\
\hline Crossover to the femoral approach & $3(30)$ \\
\hline Patients with successful snuffbox puncture & 128 \\
\hline Success rate of diagnostic CAG & $128(100)$ \\
\hline Success rate of primary PCI & $128(100)$ \\
\hline
\end{tabular}

respectively. A total of 19 patients (14.8\%) had $\geq$ grade 3 chronic kidney disease, defined as an estimated glomerular filtration rate of $<60 \mathrm{~mL} / \mathrm{min} / 1.73 \mathrm{~m}^{2}$. There were 113 patients (88.3\%) with Killip classification $\leq 2$, and the mean left ventricular ejection fraction was $50.8 \pm 10.0 \%$.

Procedural characteristics including the details of the DRA and 30-day mortality data are presented in Table 3. With respect to the details of the DRA, the mean and median times of snuffbox puncture, defined as the time interval from local anesthesia induction to successful sheath cannulation, were $2.7 \pm 1.6$ and 2.0 minutes (quartile 1 to $3: 2.0$ to 3.0), respectively. Snuffbox puncture was done within 3 and 5 minutes in 81.3\% (104/128) and 95.3\% (122/128) of patients, respectively (Fig. 2). With respect to the safety of the DRA for primary PCI, the percentage of the puncture time in the $\mathrm{D} 2 \mathrm{~B}$ time was evaluated and the percentage was 3.3\% (quartile 1 to 3: 2.6 to 4.5) (Fig. 3). The left DRA was selected in 103 patients (80.5\%), and primary PCI via the DRA was performed using a 6-Fr guiding catheter in 125 patients (97.7\%). In three patients (2.3\%), 6.5-Fr sheathless guiding catheter was used. With respect to lesion characteristics, 50.8\% (65/128) of culprit lesions were located in the left anterior descending artery and the proportion of type B2/C was $94.5 \%$ (121/128). Implantation of $>2$ stents and multivessel PCI were performed in $36(28.1 \%)$ and 20 patients (15.6\%), respectively. Thrombus aspiration was needed in 62 patients $(48.4 \%)$ 
Table 2. Baseline clinical characteristics of the study population $(n=128)$

\begin{tabular}{|c|c|}
\hline Characteristic & Value \\
\hline \multicolumn{2}{|l|}{ Demographics } \\
\hline Age, yr & $62.3 \pm 10.8$ \\
\hline Men & $109(85.2)$ \\
\hline Height, cm & $166.0 \pm 8.0$ \\
\hline Weight, kg & $68.7 \pm 11.7$ \\
\hline BMI, $\mathrm{kg} / \mathrm{m}^{2}$ & $24.8 \pm 3.1$ \\
\hline \multicolumn{2}{|l|}{ Vital signs } \\
\hline Systolic blood pressure, mmHg & $129.4 \pm 23.2$ \\
\hline Diastolic bleed pressure, $\mathrm{mmHg}$ & $79 \cdot 5 \pm 15 \cdot 5$ \\
\hline Heart rate, bpm & $77.8 \pm 17.4$ \\
\hline \multicolumn{2}{|l|}{ Time to primary PCI } \\
\hline Symptom-to-balloon time, min & $172(112-363)$ \\
\hline Door-to-balloon time, min & $70(58-81)$ \\
\hline \multicolumn{2}{|l|}{ Risk factors } \\
\hline Hypertension & $65(50.8)$ \\
\hline Diabetes mellitus & $42(32.8)$ \\
\hline Dyslipidemia & $42(32.8)$ \\
\hline Current smoking & $64(50.0)$ \\
\hline Chronic kidney disease $\geq$ grade $3^{\mathrm{a}}$ & $19(14.8)$ \\
\hline History of CVA & $8(6.3)$ \\
\hline History of MI & $10(7.8)$ \\
\hline History of PCI & $18(14.1)$ \\
\hline Killip class $\leq 2$ & $113(88.3)$ \\
\hline LVEF, \% & $50.8 \pm 10.0$ \\
\hline \multicolumn{2}{|l|}{ Laboratory findings } \\
\hline Hemoglobin, g/dL & $14 \cdot 5 \pm 2.1$ \\
\hline Platelets, $10^{3} / \mathrm{mm}^{3}$ & $246 \pm 62$ \\
\hline PT-INR & $1.0 \pm 0.1$ \\
\hline
\end{tabular}

\begin{tabular}{|cc}
\hline Characteristic & Value \\
\hline Total cholesterol, mg/dL & $173.3 \pm 48.0$ \\
\hline Triglycerides, mg/dL & $168.8 \pm 109.6$ \\
\hline HDL-C, mg/dL & $41.1 \pm 9.6$ \\
\hline LDL-C, mg/dL & $109.4 \pm 37.9$ \\
\hline Serum creatinine, mg/dL & $1.1 \pm 0.8$ \\
\hline eGFR, mL/min/1.73 m ${ }^{2}$ & $83.2 \pm 27.1$ \\
\hline Peak CK-MB, ng/mL & $155.5 \pm 105.6$ \\
\hline Peak troponin I, ng/mL & $70.1 \pm 67.6$ \\
\hline Medications at discharge & \\
\hline Aspirin & $128(100)$ \\
\hline P2Y ${ }_{12}$ receptor inhibitor & $127(99.2)$ \\
\hline Clopidogrel & $14(11.0)$ \\
\hline Ticagrelor & $79(62.2)$ \\
\hline Prasugrel & $34(26.8)$ \\
\hline ACE inhibitor or ARB & $107(83.6)$ \\
\hline Beta-blocker & $103(80.5)$ \\
\hline Statin & $124(96.9)$ \\
\hline
\end{tabular}

Values are presented as mean $\pm \mathrm{SD}$, number (\%), or median (interquartile range).

BMI, body mass index; PCI, percutaneous coronary intervention; CVA, cerebrovascular accident; MI, myocardial infarction; LVEF, left ventricular ejection fraction; PT-INR, prothrombin time-international normalized ratio; HDL-C, high density lipoprotein cholesterol; LDL-C, low density lipoprotein cholesterol; eGFR, estimated glomerular filtration rate; CK-MB, creatine kinase-myocardial band; ACE, angiotensin-converting enzyme; $\mathrm{ARB}$, angiotensin receptor blocker.

${ }^{\mathrm{a}}$ Chronic kidney disease $\geq$ grade 3 was defined as eGFR $<60$ $\mathrm{mL} / \mathrm{min} / 1.73 \mathrm{~m}^{2}$.

and intravascular imaging-guided PCI was conducted in 53 patients (41.4\%) (intravascular ultrasound in 45 and optical coherence tomography guidance in eight).

During primary PCI, temporary pacemaker, requiring inguinal preparation, was inserted in two (1.6\%), but there was no case of inserted intra-aortic balloon pump via the femoral approach. In terms of the guiding catheter for the procedure, the extra-backup-type catheter was used in 91 of 89 cases (91.0\%) of left coronary artery lesion. Among 47 cases of right coronary artery lesion, Judkins right and Amplatz type catheters were used in 25 (53.2\%) and 22 cases (46.8\%), respectively. Concerning the clinical outcome,

the overall incidence of death at 30 days was $2.0 \%$ (2/100), including two cases of in-hospital cardiac death.

With respect to puncture-site complications, local hematoma (EASY classification I) occurred in three patients (2.3\%). One patient (0.8\%) experienced puncture-related local numbness, but it improved after 3 months. There was no bleeding complication requiring surgery or transfusion. Furthermore, major bleeding, defined as Thrombolysis in Myocardial Infarction major bleeding or Bleeding Academic Research Consortium ₹3, was not observed (Table 4). 
Table 3. Procedural characteristics and 30-day mortality $(n=128)$

\begin{tabular}{|c|c|}
\hline Characteristic & Value \\
\hline \multicolumn{2}{|l|}{ Distal radial approach details } \\
\hline \multicolumn{2}{|l|}{ Puncture time, $\min$} \\
\hline Mean \pm SD & $2.7 \pm 1.6$ \\
\hline Median (IQR) & $2.0(2.0-3.0)$ \\
\hline Puncture time $<3 \mathrm{~min}$ & $80(81.3)$ \\
\hline Puncture time $<5$ min & $122(95 \cdot 3)$ \\
\hline $\begin{array}{l}\text { Proportion of snuffbox puncture time } \\
\text { to } \mathrm{D}_{2} \mathrm{~B} \text { time, } \%\end{array}$ & $3 \cdot 3(2.6-4 \cdot 5)$ \\
\hline Left distal radial approach & $103(80.5)$ \\
\hline $\begin{array}{l}\text { Use of } 6 \text {-Fr guiding catheter for } \\
\text { primary PCI }\end{array}$ & $125(97 \cdot 7)$ \\
\hline $\begin{array}{l}\text { Use of } 6.5 \text {-Fr sheathless guiding } \\
\text { catheter for primary PCI }\end{array}$ & $3(2.3)$ \\
\hline \multicolumn{2}{|l|}{ Lesion characteristics } \\
\hline \multicolumn{2}{|l|}{ Culprit lesion } \\
\hline Left anterior descending artery & $65(50.8)$ \\
\hline Left circumflex artery & $16(12.5)$ \\
\hline Right coronary artery & $47(36.7)$ \\
\hline Left main coronary artery & o \\
\hline ACC/AHA type B2/C lesion & $121(94 \cdot 5)$ \\
\hline Pre-PCI TIMI grade flow o-1 & $92(71.9)$ \\
\hline Stent failure & $10(7.8)$ \\
\hline Multivessel disease & $75(58.6)$ \\
\hline \multicolumn{2}{|l|}{ Primary PCI details } \\
\hline PCI with stent implantation & $122(95 \cdot 3)$ \\
\hline
\end{tabular}

\section{DISCUSSION}

In this study on patients with STEMI undergoing primary PCI via the DRA, the success rate of snuffbox puncture was $92.8 \%$. However, primary PCI via the DRA was successfully performed in all 128 patients. The snuffbox puncture time was $2.7 \pm 1.6$ minutes, and the percentage of the puncture time in the $\mathrm{D}_{2} \mathrm{~B}$ time was $3.3 \%$. The occurrence rate of puncture-site complications was low, and no major bleeding complication was observed. To our knowledge, this is the first study to report the feasibility of the DRA for primary PCI in the setting of STEMI.

Recently, there have been several studies on the feasibility of the DRA as shown in Table 5. Kiemeneij [7] reported that the success rate of the DRA was $89.0 \%$ in

\begin{tabular}{|c|c|}
\hline Characteristic & Value \\
\hline Total no. of implanted stents & $1.4 \pm 0.8$ \\
\hline Cases with implantation of $\geq 2$ stents & $36(28.1)$ \\
\hline Multivessel PCI & $20(15.6)$ \\
\hline Thrombus aspiration & $62(48.4)$ \\
\hline Intravascular imaging-guided PCI & $53(41.4)$ \\
\hline IVUS guidance & $45(35.2)$ \\
\hline OCT guidance & $8(6.3)$ \\
\hline Temporary pacemaker & $2(1.6)$ \\
\hline Intra-aortic balloon pump & o \\
\hline Total procedure time, min & $43.2 \pm 15.1$ \\
\hline Total contrast volume, mL & $155.4 \pm 42.8$ \\
\hline \multicolumn{2}{|l|}{ Left guiding catheter $(n=89)$} \\
\hline EBU type & $81(91.0)$ \\
\hline Judkins left type & $5(5.6)$ \\
\hline Others & $3(3 \cdot 4)$ \\
\hline \multicolumn{2}{|l|}{ Right guiding catheter $(n=47)$} \\
\hline Judkins right type & $25(53.2)$ \\
\hline Amplatz type & $22(46.8)$ \\
\hline 30-Day mortality & $2(1.6)$ \\
\hline \multicolumn{2}{|c|}{$\begin{array}{l}\text { Values are presented as mean } \pm \mathrm{SD} \text {, median (interquartile } \\
\text { range), or number (\%). } \\
\text { D2B, door-to-balloon; PCI, percutaneous coronary inter- } \\
\text { vention; ACC, American College of Cardiology; AHA, Amer- } \\
\text { ican Heart Association; TIMI, Thrombolysis in Myocardial } \\
\text { Infarction; IVUS, intravascular ultrasound; OCT, optical } \\
\text { coherence tomography; EBU, extra backup. }\end{array}$} \\
\hline
\end{tabular}

70 selected patients with a good pulsation of the distal radial artery. In our previous retrospective and prospective studies, the success rate was $88.0 \%(132 / 150)$ and $95.5 \%$ (191/200), respectively $[8,9]$. Several other studies have also reported an $89.8 \%$ to $100 \%$ success rate of the DRA [11-14]. However, these studies enrolled a small number of patients with STEMI. Considering the setting of STEMI, the success rate of the DRA (92.8\%) in the present study may be acceptable. Interestingly, seven patients among 10 patients in whom the DRA failed were converted to the conventional radial approach. Even if the DRA failed, it could provide an opportunity for the conventional radial approach, which is recommended over the femoral approach in patients with acute myo- 


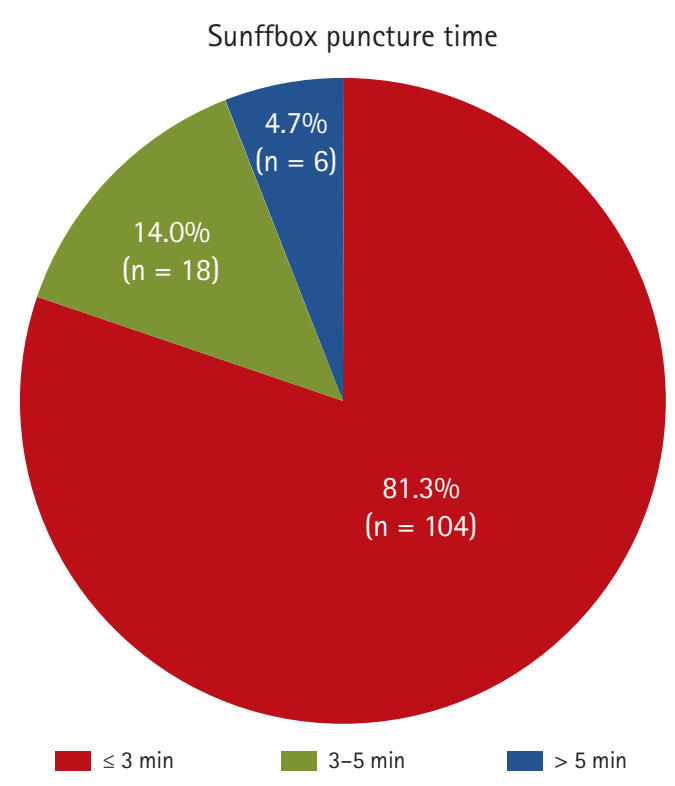

Figure 2. Distribution of the snuffbox puncture time in 128 patients who underwent a successful primary percutaneous coronary intervention via the distal radial approach (Snuffbox puncture time was defined as time interval from local anesthesia induction to successful sheath cannulation).

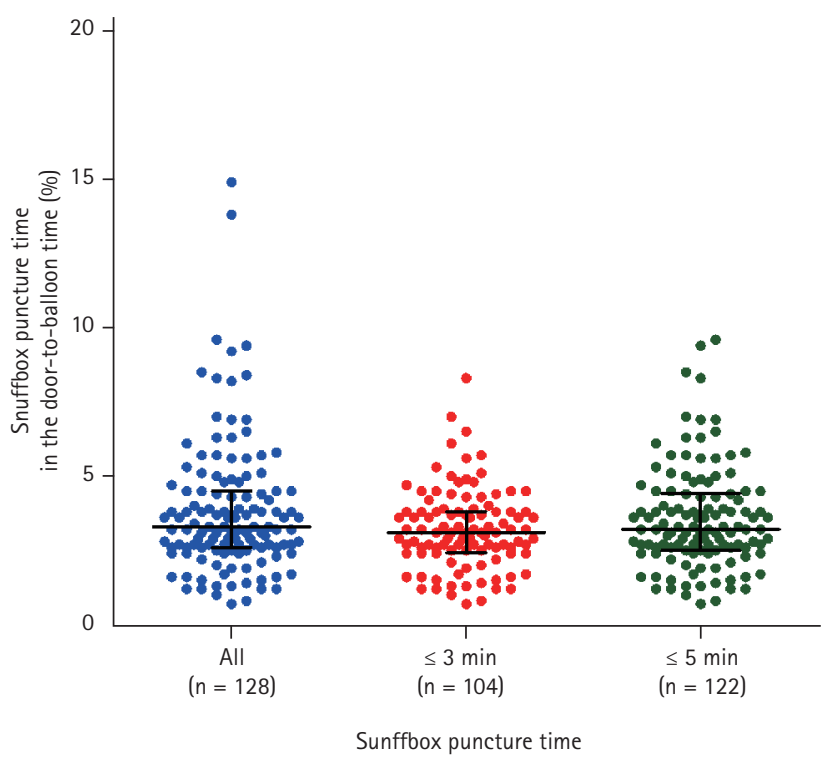

Figure 3. Percentage of the snuffbox puncture time in the door-to-balloon time (Horizontal lines represent median with interquartile range).

cardial infarction including STEMI, as described in the current guidelines $[5,6]$. With respect to the snuffbox puncture time, the mean puncture time in our study was $2.7 \pm 1.6$ minutes. In previous studies, snuffbox puncture
Table 4. Periprocedural antithrombotic treatment and complications $(\mathbf{n}=\mathbf{1 2 8})$

\begin{tabular}{|cc}
\hline Variable & Value \\
\hline Periprocedural antithrombotic treatment & \\
\hline Aspirin loading & $111(86.7)$ \\
\hline P2Y $_{12}$ receptor inhibitor loading & $125(98.4)$ \\
\hline Clopidogrel & $14(11.1)$ \\
\hline Ticagrelor & $78(61.9)$ \\
\hline Prasugrel & $34(27.0)$ \\
\hline UFH or LMWH injection & $128(100)$ \\
\hline Glycoprotein IIb/IIIa inhibitor & $40(31.3)$ \\
\hline during primary PCI & $4(3.1)$ \\
\hline Oral anticoagulant & \\
\hline Puncture-site and bleeding complications & 0 \\
\hline Any bleeding complication requiring & \\
\hline surgery or transfusion & $4(3.1)$ \\
\hline Puncture-site complication & $3(2.3)$ \\
\hline Local hematoma (EASY classification I) & $1(0.8)$ \\
\hline Local numbness & \\
\hline Bleeding complication & $3(2.3)$ \\
\hline BARC bleeding type 1 & 0 \\
\hline BARC bleeding type 2 & \\
\hline BARC bleeding type $\geq 3$ & \\
\hline TIMI minimal bleeding & \\
\hline TIMI major bleeding & \\
\hline
\end{tabular}

Values are presented as number (\%).

UFH, unfractionated heparin; LMWH, low molecular weight heparin; PCI, percutaneous coronary intervention; EASY, Early Discharge After Transradial Stenting of Coronary Artery; BARC, Bleeding Academic Research Consortium; TIMI, Thrombolysis In Myocardial Infarction.

time was checked 1.19 to 3.9 minutes $[9,11,12]$. Thus, the present study seemed to be acceptable snuffbox puncture time, but it is difficult to directly compare snuffbox puncture time between the present study and other studies as the definition of snuffbox puncture time was not suggested in previous studies. Further large-scale study of the DRA, having a unified definition, is needed to compare snuffbox puncture time in patients presenting with STEMI. Although there is some concern that this new puncture technique might delay the $\mathrm{D} 2 \mathrm{~B}$ time in patients presenting with STEMI, it was not observed in the present study. Moreover, the median percentage 
Table 5. Summary of published studies on the distal radial approach

\begin{tabular}{|c|c|c|c|c|c|}
\hline Study & $\begin{array}{l}\text { No. of } \\
\text { patients }\end{array}$ & $\begin{array}{l}\text { Mean } \\
\text { age, yr }\end{array}$ & $\begin{array}{l}\text { Patients with } \\
\text { STEMI }\end{array}$ & $\begin{array}{l}\text { Success rate of the } \\
\text { distal radial approach }\end{array}$ & $\begin{array}{l}\text { Major } \\
\text { bleeding }\end{array}$ \\
\hline Kiemeneij (2017) [7] & 70 & $68 \pm 11$ & $9.0(6 / 70)$ & $89.0(62 / 70)$ & $\mathrm{o}(0)$ \\
\hline Kim et al. (2018) [8] & 150 & $66 \pm 13$ & $1.5(2 / 132)$ & $88.0(132 / 180)$ & $\mathrm{o}(0)$ \\
\hline Lee et al. (2018) [9] & 200 & $66 \pm 12$ & $8.5(17 / 200)$ & $95.5(191 / 200)$ & $\mathrm{o}(0)$ \\
\hline Ziakas et al. (2018) [11] & 49 & $64 \pm 12$ & $6.1(3 / 49)$ & $89.8(44 / 49)$ & $\mathrm{o}(0)$ \\
\hline Soydan et al. (2018) [12] & 54 & $59 \pm 12$ & $18.5(10 / 54)$ & $100.0(54 / 54)$ & $\mathrm{o}(\mathrm{o})$ \\
\hline Valsecchi et al. (2018) [13] & 52 & $68 \pm 12$ & No record & $90.0(47 / 52)$ & $\mathrm{o}(0)$ \\
\hline Norimatsu et al. (2019) [14] & 74 & $70 \pm 11$ & $\mathrm{o}(\mathrm{o} / 74)$ & $91.9(68 / 74)$ & $\mathrm{o}(\mathrm{o})$ \\
\hline
\end{tabular}

Values are presented as mean \pm SD or percentage (number).

STEMI, ST-elevation myocardial infarction.

of the snuffbox puncture time in the $\mathrm{D} 2 \mathrm{~B}$ time was only $3.3 \%$ without delaying the $\mathrm{D} 2 \mathrm{~B}$ time to $>90$ minutes. Given the snuffbox puncture success rate, the puncture time, and the effect of puncture time on the $\mathrm{D} 2 \mathrm{~B}$ time, the DRA might be feasible as an alternative access route in patients with STEMI.

As shown in Fig. 3, this study analyzed the percentage of the snuffbox puncture time in the $\mathrm{D} 2 \mathrm{~B}$ time according to the puncture time. $A>10 \%$ of the snuffbox puncture time in the D2B time was observed in two of 128 patients in whom the DRA was successfully used. On the other hand, the percentage was $<10 \%$ in all patients in whom a successful snuffbox puncture was achieved within 5 minutes. On the basis of our study results, delayed puncture ( $>5$ minutes) could be considered an indication of the need to change the puncture-site for the safety of patients.

Data on the DRA for primary PCI remains limited, and only a few cases have been reported $[15,16]$. Furthermore, several studies have demonstrated that the diameter of the distal radial artery is relatively smaller than that of the conventional radial artery, thus raising the concern about whether the DRA can be as feasible as the conventional radial approach $[8,9,13,14,17]$. In our study, successful primary PCI was performed without a change in access-site in all 128 patients in whom successful snuffbox puncture was achieved. In addition, the present study showed the feasibility of the DRA for implantation of $\geq 2$ stents, multivessel PCI, and imaging-guided PCI in patients with STEMI, by using 6 -Fr guiding catheters similar to those used in the conventional radial approach. The feasibility of this new approach, similar to that of the conventional radial approach, could be explained by the choice of the left DRA in most of the present study population. Although most radial operators prefer the right radial approach because of the working position and for the operator's convenience, the higher incidence of right subclavian tortuosity results in a longer fluoroscopic time and more contrast use [18]. Accordingly, the left DRA can facilitate easier catheter manipulation and save time and contrast in emergency situations, owing to the less tortuous subclavian artery.

Several studies have demonstrated that major bleeding did not occur in patients who underwent CAG and PCI via the DRA [7-9,11-14,19]. In the present study, new $\mathrm{P}_{2} \mathrm{Y}_{12}$ receptor inhibitors, including ticagrelor and prasugrel, were loaded before primary PCI in about $90 \%$ of patients and unfractionated heparin was used during primary PCI in all 128 patients. Furthermore, a glycoprotein IIb/IIIa inhibitor was used during primary PCI in one-third of the patients. Despite the potent peri-procedural antithrombotic treatment, there were no cases of major bleeding complication requiring blood transfusion or surgical repair. This study reaffirms the potential benefit of the DRA in terms of bleeding complication, as demonstrated in previous studies. Therefore, the DRA could be considered an alternative access route in patients with a high bleeding risk or those in whom bleeding complications need to be minimized.

There were several limitations in the present study. 
First, this study has the inherent limitations of retrospective studies with a small sample size. In addition, operators tried to perform the DRA in patients with well-palpable distal radial artery. Therefore, selection bias might have influenced the results and our results should be carefully interpreted. Second, the feasibility of the DRA in the setting of STEMI was evaluated without a control group. Therefore, large multicenter randomized trials comparing the DRA with the conventional radial approach are needed in the future. Third, two different types of puncture needles were used for the DRA according to the operator's preference, and this might have affected the success rate and the snuffbox puncture time. Fourth, although a reduction in the risk of distal and conventional radial artery occlusion is a potential benefit of the DRA, the occurrence rate of radial artery occlusion was not evaluated in this study.

In conclusion, the DRA for primary PCI in the setting of STEMI was feasible in terms of the puncture success rate, puncture time, and procedure success rate on the basis of our experience. Moreover, this new approach showed a low occurrence rate of bleeding complications even in patients treated with potent antithrombotic medications. Further large randomized control trials are needed to confirm the feasibility and safety of the DRA for primary PCI.

\section{KEY MESSAGE}

1. On the basis of retrospective data at three hospitals from October 2017 to September 2019, the success rate of the distal radial approach for primary percutaneous coronary intervention, was $92.8 \%$ in patients with ST-elevation myocardial infarction.

2. The snuffbox puncture time, defined as the time interval from local anesthesia induction to successful sheath cannulation, was $2.7 \pm 1.6$ minutes, and snuffbox puncture was performed within 5 minutes in $95.3 \%$ of patients.

3. Among total of 128 study population, the occurrence rate of puncture-site complications was only $3.1 \%$ including three cases of local hematoma ( $\leq 5 \mathrm{~cm}$ diameter) and one case of local numbness, but no major bleeding complication was observed.

\section{Conflict of interest}

No potential conflict of interest relevant to this article was reported.

\section{Acknowledgments}

This work was supported by a grant from the National Research Foundation of Korea (NRF-2019R1A2C3003547) and by a grant from Chonnam National University Hospital Biomedical Research Institute (BCRI18015 \& BCRI19009).

\section{REFERENCES}

1. Jolly SS, Yusuf S, Cairns J, et al. Radial versus femoral access for coronary angiography and intervention in patients with acute coronary syndromes (RIVAL): a randomised, parallel group, multicentre trial. Lancet 2011;377:1409-1420.

2. Valgimigli M, Gagnor A, Calabro P, et al. Radial versus femoral access in patients with acute coronary syndromes undergoing invasive management: a randomized multicentre trial. Lancet 2015;385:2465-2476.

3. Ferrante G, Rao SV, Juni P, et al. Radial versus femoral access for coronary interventions across the entire spectrum of patients with coronary artery disease: a meta-analysis of randomized trials. JACC Cardiovasc Interv 2016;9:1419-1434.

4. Valgimigli M, Frigoli E, Leonardi S, et al. Radial versus femoral access and bivalirudin versus unfractionated heparin in invasively managed patients with acute coronary syndrome (MATRIX): final 1-year results of a multicentre, randomised controlled trial. Lancet 2018;392:835848.

5. Neumann FJ, Sousa-Uva M, Ahlsson A, et al. 2018 ESC/ EACTS guidelines on myocardial revascularization. Eur Heart J 2019;40:87-165.

6. Ibanez B, James S, Agewall S, et al. 2017 ESC guidelines for the management of acute myocardial infarction in patients presenting with ST-segment elevation: the task force for the management of acute myocardial infarction in patients presenting with ST-segment elevation of the European Society of Cardiology (ESC). Eur Heart J 2018;39:119-177.

7. Kiemeneij F. Left distal transradial access in the anatomical snuffbox for coronary angiography (ldTRA) and inter- 
ventions (ldTRI). EuroIntervention 2017;13:851-857.

8. Kim Y, Ahn Y, Kim I, et al. Feasibility of coronary angiography and percutaneous coronary intervention via left snuffbox approach. Korean Circ J 2018;48:1120-1130.

9. Lee JW, Park SW, Son JW, Ahn SG, Lee SH. Real-world experience of the left distal transradial approach for coronary angiography and percutaneous coronary intervention: a prospective observational study (LeDRA). EuroIntervention 2018;14:e995-e1003.

10. Rao SV, Bernat I, Bertrand OF. Clinical update: remaining challenges and opportunities for improvement in percutaneous transradial coronary procedures. Eur Heart J 2012;33:2521-6.

11. Ziakas A, Koutouzis M, Didagelos M, et al. Right arm distal transradial (snuffbox) access for coronary catheterization: initial experience. Hellenic J Cardiol 2020;61:106109.

12. Soydan E, Akın M. Coronary angiography using the left distal radial approach: an alternative site to conventional radial coronary angiography. Anatol J Cardiol 2018;19:243248.

13. Valsecchi O, Vassileva A, Cereda AF, et al. Early clinical experience with right and left distal transradial access in the anatomical snuffbox in 52 consecutive patients. J Invasive Cardiol 2018;30:218-223.

14. Norimatsu K, Kusumoto T, Yoshimoto K, et al. Impor- tance of measurement of the diameter of the distal radial artery in a distal radial approach from the anatomical snuffbox before coronary catheterization. Heart Vessels 2019;34:1615-1620.

15. Kim Y, Jeong MH, Berezhnoi K, et al. Recannulation of distal radial artery for staged procedure after successful primary percutaneous coronary intervention. J Invasive Cardiol 2018;30:E105-E106.

16. Kim Y, Jeong MH, Kim MC, et al. Successful primary percutaneous coronary intervention in patient with ST-segment elevation myocardial infarction via left snuffbox approach: patient advantages. Cardiol J 2019;26:198-199.

17. Corcos T. Distal radial access for coronary angiography and percutaneous coronary intervention: a state-of-theart review. Catheter Cardiovasc Interv 2019;93:639-644.

18. Guo X, Ding J, Qi Y, et al. Left radial access is preferable to right radial access for the diagnostic or interventional coronary procedures: a meta-analysis involving 22 randomized clinical trials and 10287 patients. PLoS One 2013;8:e78499.

19. Gasparini GL, Garbo R, Gagnor A, Oreglia J, Mazzarotto P. First prospective multicentre experience with left distal transradial approach for coronary chronic total occlusion interventions using a 7 Fr Glidesheath Slender. EuroIntervention 2019;15:126-128. 